\title{
AL-NAFS DALAM AL-QUR'AN: MAKNA, MACAM DAN KARAKTERISTIKNYA
}

\author{
Muhammad Arwani Rofi'i
}

Sekolah Tinggi Ilmu al-Qur'an dan Sains Al-Ishlah (STIQSI)

Sendangagung Paciran Lamongan

Email: mafaza@alishlah.ac.id

\begin{abstract}
Abstrak
Tulisan ini bertujuan untuk menjelaskan makna kata al-nafs dalam alQur'an disertai macam dan karekteristiknya. Dalam al-Qur'an terdapat 295 kata nafs dalam berbagai bentuknya. Kata nafs mempunyai makna yang beragam dalam al-Qur'an; mulai dari ruh, dzat, darah pembeda, dan lainnya. Namun, makna yang sering digunakan untuk memaknai nafs adalah manusia seutuhnya; jasadnya, raganya, akalnya, hatinya dan segala hal yang menjadi bagian dari manusia. Nafs mempunyai ciri, sifat dan karakteristik yang beragam walaupun hakikatnya diciptakan dari dzat yang satu, yaitu Adam. Perbedaan ciri, sifat dan karakteristik tersebut dapat dipengaruhi oleh lingkungan dan budaya tempat ia berada. Di antara ciri nafs adalah tergesa-gesa, lemah, dapat membedakan antara yang baik dan buruk. Sedangkan sifat nafs di antaranya adalah tawadu, makan, minum, berbohong. Adapun karakteristik nafs di antaranya adalah mempunyai insting alami untuk mengetahui hakikat sang pencipta.
\end{abstract}

Kata Kunci: al-Nafs.

\section{Pendahuluan}

Al-Qur'an adalah obat penawar yang sempurna bagi segala macam penyakit, baik itu penyakit jiwa maupun penyakit raga. Obat dalam perkara duniawi maupun perkara akhirat. Tidak ada penyakit dari segala jenis penyakit raga maupun jiwa manusia yang tidak ada obatnya dalam al-Qur'an. Di dalamnya terdapat petunjuk, hikmah dan pesan-pesan untuk kebaikan manusia sebagaimana firman Allah dalam surah al-Isra' (17) ayat 82 berikut ini:

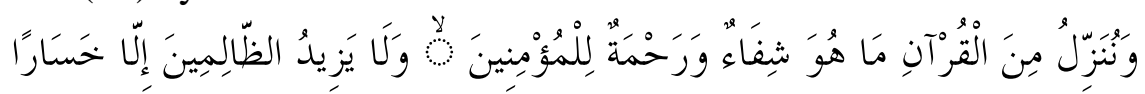

Dan Kami turunkan dari Al Quran suatu yang menjadi penawar dan rahmat bagi orang-orang yang beriman dan Al Quran itu tidaklah menambah kepada orang-orang yang zalim selain kerugian.

Dan Firman Allah dalam surat Yunus (10) ayat 57 berikut ini:

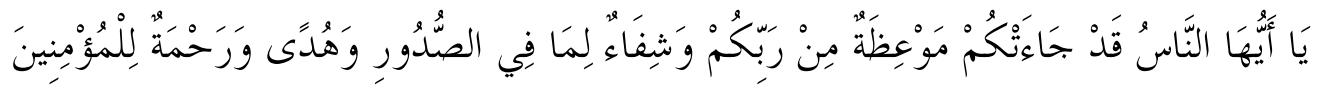

Hai manusia, sesungguhnya telah datang kepadamu pelajaran dari Tuhanmu dan penyembuh bagi penyakit-penyakit (yang berada) dalam dada dan petunjuk serta rahmat bagi orang-orang yang beriman. 
Al-Qur'an sangat memperhatikan jiwa manusia karena pada dasarnya hidayah, hikmah dan pesan-pesan yang terdapat dalam al-Qur'an tujuannya adalah untuk manusia. Maka jika manusia ingin sampai kepada hal-hal tersebut seharusnya ia mampu mengungkap jiwanya agar jelas segala sisi yang terdapat dalam dirinya.

Jiwa manusia sesuai dengan makna qur'ani mencakup dua macam kekuatan, yaitu baik dan buruk. Akan tetapi manusia lebih condong kepada kebaikan, maka manusia lebih cenderung mengikuti kebaikan. Di samping itu dalam jiwa manusia juga terdapat petunjuk untuk mengikuti perkara yang hak dan petunjuk yang benar sebagaimana ia juga mungkin terjerumus dalam kebatilan dan kerusakan. Maka, iman yang kuat mempunyai pengaruh yang besar terhadap jiwa manusia dalam kehidupannya.

\section{Pengertian Nafs dalam al-Qur'an}

Kata nafs secara bahasa mempunyai beberapa arti, di antaranya adalah sebagai berikut:

1. Ruh (nyawa), seperti perkataan kharajat nafs fulan, ay ruhuh (telah keluar jiwa seseorang, yaitu ruhnya) sebagaimana firman Allah dalam surah al-An'am (6) ayat 93 berikut:

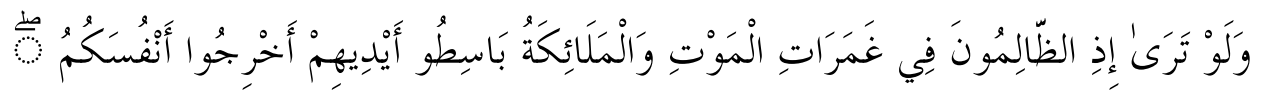

"Alangkah dahsyatnya Sekiranya kamu melihat di waktu orang-orang yang zalim berada dalam tekanan sakratul maut, sedang Para Malaikat memukul dengan tangannya, (sambil berkata): "Keluarkanlah nyawamu"

2. Hakikat atau dzat sesuatu, seperti ungkapan qutila fulan nafsuh, ay dzatuh (telah terbunuh seseorang jiwanya, yaitu dzatnya) sebagaimana firman Allah dalam surat Ali 'Imran (3) ayat 185:

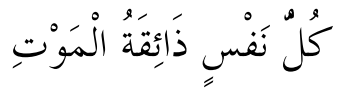

Tiap-tiap yang berjiwa akan merasakan mati.

3. Dengki, seperti perkataan asabathu nafsun (dia telah mendapatkan rasa dengki)

4. Darah, al-nafs disebut dengan darah karena al-nafs akan keluar apabila darah keluar

5. al-Tamyiz (pembeda), karena jiwa dapat membedakan antara dua hal, terkadang ia memerintahkan suatu hal di lain kesempatan ia melarang hal tersebut. ${ }^{1}$

Itu adalah beberapa arti secara bahasa dari kata al-nafs. Terdapat arti yang dekat dengan pembahasan ini, namun terdapat juga arti yang jauh dari pembahasan dalam makalah ini. Kata nafs merupakan bentuk mufrod (singular), sedangkan bentuk jama' (plural)-nya adalah anfus dan nufus. Kata nafs dengan berbagai bentuknya dalam al-Qur'an disebutkan sebanyak 295 kali dengan berbagai makna

${ }^{1}$ Nu'aymah 'Abd Allah al-Barash, Afat al-Nafs Kama Yusawwiruha al-Qur'an al-Karim (Gaza: Maktabah al-Jami’ah al-Islamiyyah, 2008), 9-10. 
yang terkandung dari kata tersebut. ${ }^{2}$ Di antara beberapa bentuk kata yang diambil dari nafs adalah tanaffus, nafsan, nafsy, anfusukum, falyatanafas, nafsuka, al-nufus, anfusuhum, al-mutanafisun, nafsahu, nufusukum, anfusuna, nafsun, nafsuha, alanfus, anfusuhunna yang berjumlah 16 bentuk. $^{3}$

Sedangkan pengertian nafs menurut istilah yang sesuai dengan makna yang terkandung dalam ayat-ayat al-Quran di antaranya adalah sebagai berikut:

1. al-Ruh (Ruh atau Nyawa)

Kata Nafs yang berarti ruh atau nyawa terdapat dalam beberapa ayat di antaranya adalah sebagai berikut:

a. Surat al-Zumar (39) ayat 42

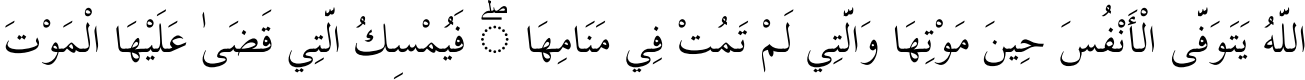

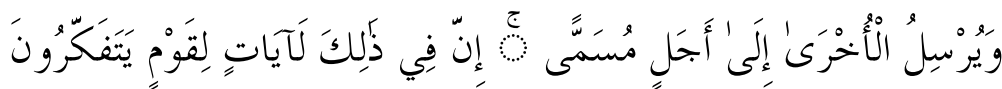

Allah memegang jiwa (orang) ketika matinya dan (memegang) jiwa (orang) yang belum mati di waktu tidurnya; Maka Dia tahanlah jiwa (orang) yang telah Dia tetapkan kematiannya dan Dia melepaskan jiwa yang lain sampai waktu yang ditetapkan 4 . Sesungguhnya pada yang demikian itu terdapat tanda- tanda kekuasaan Allah bagi kaum yang berfikir.

b. Surat al-An'am (6) ayat 93

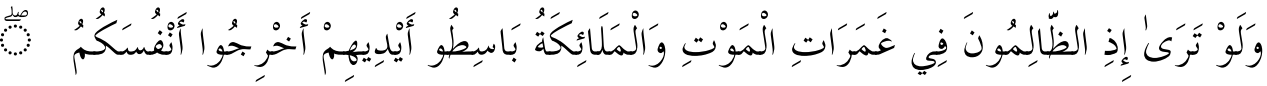

Alangkah dahsyatnya sekiranya kamu melihat di waktu orang-orang yang zalim berada dalam tekanan sakratul maut, sedang para malaikat memukul dengan tangannya, (sambil berkata): "Keluarkanlah nyawamu."

2. al-Insan (Manusia)

Yaitu manusia seutuhnya; darahnya, dagingnya dan kepribadiannya. Makna ini adalah kebanyakan yang dimaksud dalam al-Qur'an, di antaranya adalah:

a. Surat al-Baqarah (2) ayat 48

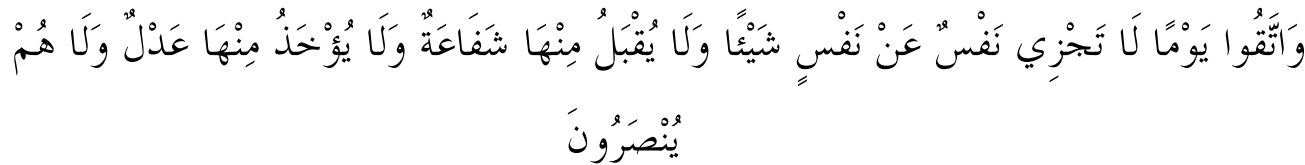

"Dan jagalah dirimu dari (azab) hari (Kiamat, yang pada hari itu) seseorang tidak dapat membela orang lain, walau sedikitpun; dan (begitu pula) tidak diterima syafa'at dan tebusan dari padanya, dan tidaklah mereka akan ditolong."

b. Surat Ali 'Imran (3) ayat 145

2 Raniya Muhammad 'Aziz Nizami, al-Nafs wa Haqiqatuha fi al-Qur'an al-Karim (Aleksandria: Maktabah Jami’ah al-Iskandariyah, 2006), 8.

${ }^{3}$ Ahmad Jum'ah Muhammad Abu Shanab, al-Nafs al-Insaniyyah fi Suwaytiha wa Inhirafiha Bayna al-Qur'an al-Karim wa 'Ilm al-Nafs al-Hadis (Saudi: Maktabah Jami'ah Um al-Qura, t.t), 6.

${ }^{4}$ Maksudnya: orang-orang yang mati itu rohnya ditahan Allah sehingga tidak dapat kembali kepada tubuhnya; dan orang-orang yang tidak mati hanya tidur saja, rohnya dilepaskan sehingga dapat kembali kepadanya lagi. 


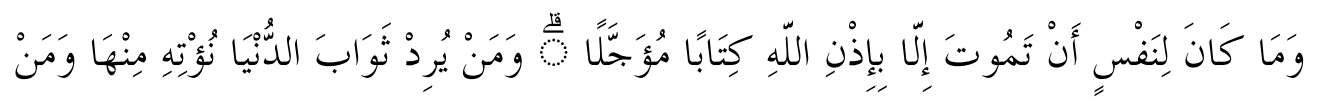

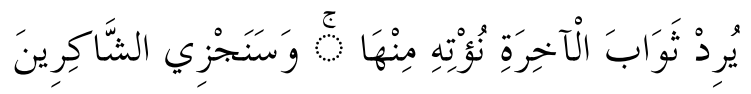

Sesuatu yang bernyawa tidak akan mati melainkan dengan izin Allah, sebagai ketetapan yang telah ditentukan waktunya. Barang siapa menghendaki pahala dunia, niscaya Kami berikan kepadanya pahala dunia itu, dan barang siapa menghendaki pahala akhirat, Kami berikan (pula) kepadanya pahala akhirat itu, dan Kami akan memberi balasan kepada orang-orang yang bersyukur.

3. Kekuatan pemikiran yang terdapat dalam manusia atau al-aql (akal)

Ayat yang mempunyai makna akal di antaranya adalah:

a. Surat al-Maidah (5) ayat 116

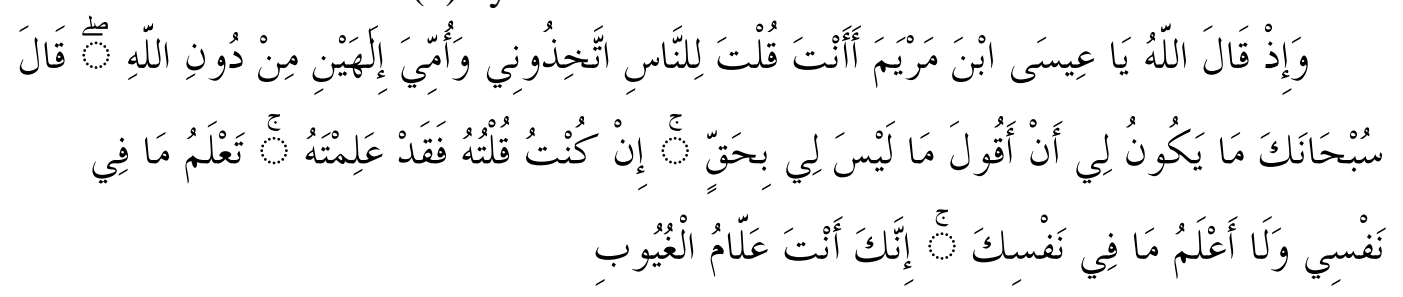

Dan (ingatlah) ketika Allah berfirman: "Hai Isa putera Maryam, adakah kamu mengatakan kepada manusia: "Jadikanlah aku dan ibuku dua Tuhan selain Allah?" Isa menjawab: "Maha suci Engkau, tidaklah patut bagiku mengatakan apa yang bukan hakku (untuk mengatakannya). Jika aku pernah mengatakan maka tentulah Engkau mengetahui apa yang ada pada diriku dan aku tidak mengetahui apa yang ada pada diri Engkau. Sesungguhnya Engkau Maha mengetahui perkara yang ghaib-ghaib".

4. Kekuatan baik dan buruk yang terdapat dalam manusia. ${ }^{5}$

Dari beberapa ayat yang ada dalam al-Qur'an dapat disimpulkan bahwa secara istilah al-nasf adalah: sesuatu yang tersusun dari dua unsur yaitu fisik dan jiwa (jasad dan ruh), dan sesuatu itu mempunyai sifat dan kemampuan yang sesuai dengan tujuannya, yaitu menyembah kepada Allah dan menjalankan tugas-tugas yang dibebankan kepadanya. Jadi dzat manusia dengan dua unsurnya itu adalah al$n a f s .{ }^{6}$

Menurut ulama kontemporer al-nafs diartikan sebagai:

1. penghubung antara ruh dan jasad

2. inti dari manusia, penggerak segala pekerjaannya yang beraneka ragam. ${ }^{7}$

Walaupun kata nafs dan berbagai bentuk kata turunannya yang tercantum dalam al-Qur'an memiliki arti yang beraneka ragam, namun arti-arti tersebut dapat dikelompokkan menjadi dua makna utama yaitu:

\footnotetext{
${ }^{5}$ al-Barash, Afat al-Nafs., 9-10.

${ }^{6}$ Walid Rashid al-'Iyasarah, Mafhum al Nafs fi al-Qur'an al-Karim wa In'ikasatuh 'Ala alMinhaj al-Tarbawy fi al-Mujtama' al-Muslim (Saudi: Maktabah Jami'ah al-Mulk, 2017), 21.

${ }^{7}$ al-Barash, Afat al-Nafs., 11.
} 
1. al-Nafs yang berarti manusia dengan berbagai sisinya, baik itu jiwa, akal, badan, dan ruh. Seperti dalam surat al-Baqarah (2) ayat 48 berikut ini:

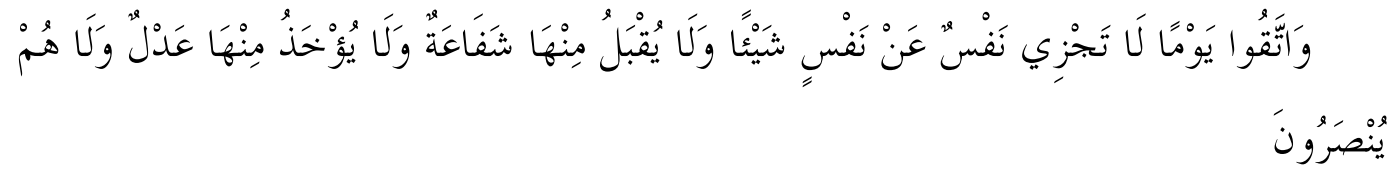

Dan jagalah dirimu dari (azab) hari (Kiamat, yang pada hari itu) seseorang tidak dapat membela orang lain, walau sedikitpun; dan (begitu pula) tidak diterima syafa'at dan tebusan dari padanya, dan tidaklah mereka akan ditolong.

Atau dalam surat al-Baqarah (2) ayat 233 berikut ini;

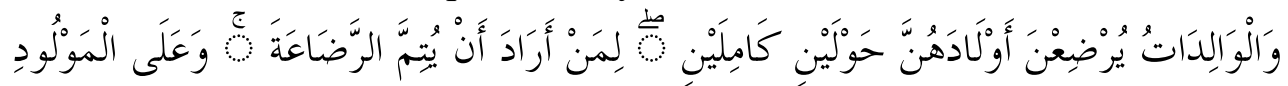

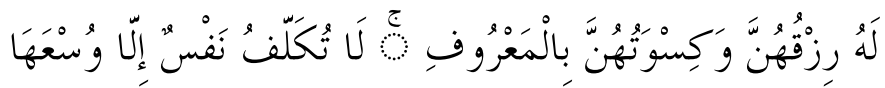

Para ibu hendaklah menyusukan anak-anaknya selama dua tahun penuh, yaitu bagi yang ingin menyempurnakan penyusuan. Dan kewajiban ayah memberi makan dan pakaian kepada para ibu dengan cara ma'ruf. Seseorang tidak dibebani melainkan menurut kadar kesanggupannya.

2. al-Nafs yang berarti ruh yang menempati badan, dan jika ia meninggalkannya maka terjadilah apa yang disebut kematian. ${ }^{8}$ Sebagaimana yang tercantum dalam surat al-Fajr (89) ayat 27 berikut ini;

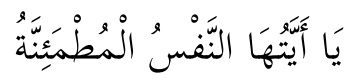

Hai jiwa yang tenang.

Atau dalam surat al-An'am (6) ayat 93 berikut ini;

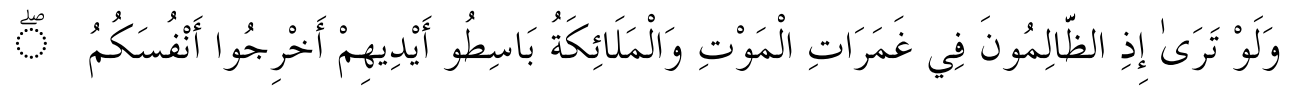

Alangkah dahsyatnya sekiranya kamu melihat di waktu orang-orang yang zalim berada dalam tekanan sakratul maut, sedang para malaikat memukul dengan tangannya, (sambil berkata): "Keluarkanlah nyawamu."

Pembagian makna nafs seperti di atas juga didukung dengan sabda Nabi Muhammad Saw. Di antara hadis yang menyatakan bahwa al-nafs berarti manusia adalah sebagai berikut:

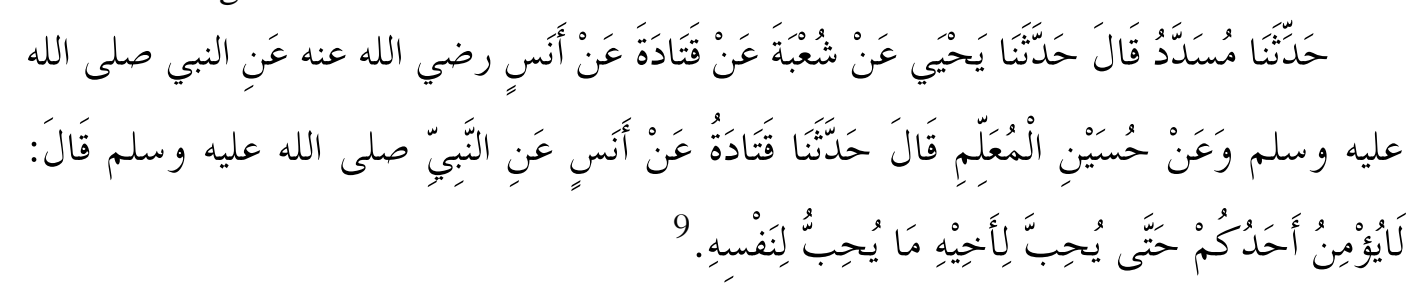

Telah menceritakan kepada kami Musaddad berkata telah menceritakan kepada kami Yahya dari Syu'bah dari Qatadah dari Anas (ra) dari Nabi Saw dan

\footnotetext{
${ }^{8}$ al-Barash, Afat al-Nafs., 23.

9 Abi Abdillah Muhammad ibn Ismail al-Bukhari, Sahih al-Bukhari (Beirut: Dar Ibn Kathir, 2002), 13-14.
} 
dari Husayn al-Mu'allim berkata telah menceritakan kepada kami Qatadah dari Anas dari Nabi Saw bersabda: Tidak beriman salah satu dari kalian sehingga mencintai saudaranya sebagaimana ia mencintai dirinya sendiri.

Sedangkan hadis yang menyatakan nafs dengan makna khusus, yaitu ruh atau nyawa adalah sebagai berikut:

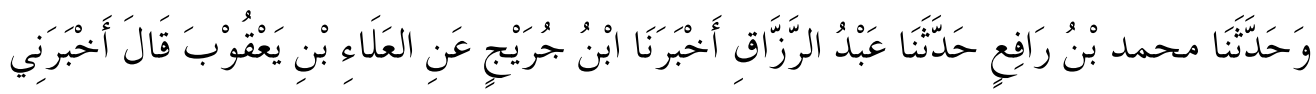

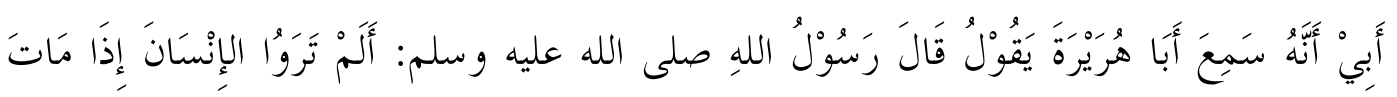

$$
\begin{aligned}
& \text { شَخَصَ بَصَرُه، قَالُو ا: بَلَى، قَالَ فَذَلِكَ حِيْنَ يَتْبَعُ بَصَرْهُ نَفْسَهُ. } 10
\end{aligned}
$$

Dan telah menceritakan kepada kami Muhammad ibn Rafi', telah menceritakan kepada kami 'Abd al-Razzaq, telah mengabarkan kepada kami Ibn Jurayj dari al-'Ala' ibn Ya'qub berkata: Telah mengabarkan kepadaku ayahku bahwasanya dia telah mendengar Aba Hurayrah berkata Rasulullah Saw bersabda: Apakah kamu tidak melihat manusia ketika mati pandangannya terangkat menatap? Mereka menjawab: Iya. Ia berkata, itu adalah ketika penglihtannya mengikuti ruhnya.

\section{Perbedaan Nafs (Jiwa), Hati, Akal, Ruh, dan Tubuh}

Manusia memiliki beberapa unsur. Selain unsur tubuh yang bersifat fisik, manusia juga memiliki unsur non-fisik seperti jiwa, hati, akal dan ruh. Agar diketahui hubungan antara jiwa, hati, akal, ruh dan badan, maka perlu kiranya dijelaskan pengertian kata-kata tersebut.

Hati (Qalb) adalah bagian inti pada diri manusia yang menjadi cermin kepribadiannya. Apabila hati itu baik, maka baik pula kepribadian manusia itu. Sebaliknya, jika hatinya buruk, maka buruk pula kepribadiannya. Sebagaimana disabdakan oleh Rasulullah Saw:

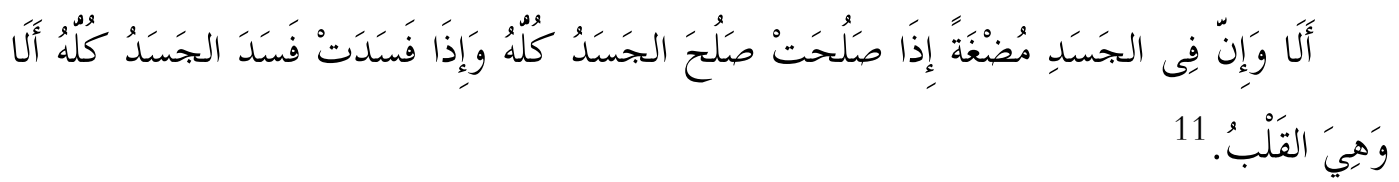

Dan sesungguhnya dalam badan ada segumpal darah, yang apabila baik maka akan baiklah semua jasadnya, akan tetapi jika rusak, maka rusaklah semua jasadnya. (Satu gumpal darah) itu tidak lain adalah hati.

Dalam al-Qur'an hati mempunyai makna yang beraneka ragam, di antaranya yang paling sering digunakan adalah hati yang bermakna tempat kesucian dan kebanaran, tempat keibaan dan emosi, tempat iman dan petunjuk. Di samping itu hati juga bisa merupakan tempat maksiat. Dilihat dari makna yang terkandung

${ }^{10}$ Abu Bakr Ahmad ibn al-Husayn ibn 'Ali al-Bayhaqi, al-Sunan al-Kubra (Beirut: Dar alKutub al-'Ilmiyyah 2002), 34.

${ }^{11}$ Ismail al-Bukhari, Shahih al-Bukhari., 24. 
dalam hati, maka pengertian nafs secara umum lebih luas cakupannya daripada hati, sedangkan nafs jika dimaknai secara khusus maka ia merupakan sinonim dari hati. ${ }^{12}$

Akal ('Aql) adalah salah satu dari bagian nafs, dan terdapat beberapa ayat dalam al-Qur'an yang menyatakan bahwa akal merupakan satu kesatuan dari pekerjaan-pekerjaan yang dilakukan oleh hati sebagaimana dalam surat al-A'raf (7) ayat 179 berikut ini:

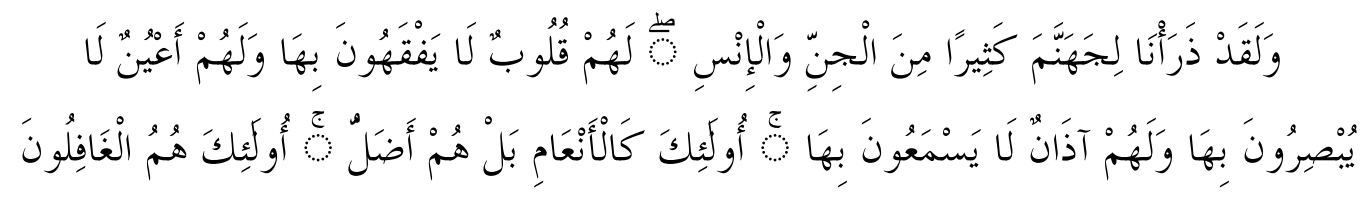

Dan sesungguhnya Kami jadikan untuk (isi neraka Jahannam) kebanyakan dari jin dan manusia. Mereka mempunyai hati, tetapi tidak dipergunakannya untuk memahami (ayat-ayat Allah), dan mereka mempunyai mata (tetapi) tidak dipergunakannya untuk melihat (tanda-tanda kekuasaan Allah), dan mereka mempunyai telinga (tetapi) tidak dipergunakannya untuk mendengar (ayat-ayat Allah). Mereka itu seperti binatang ternak, bahkan mereka lebih sesat lagi. Mereka itulah orang-orang yang lalai.

Dari ayat di atas dapat diambil kesimpulan bahwa hati mempunyai dua sisi, sisi emosional dan sisi akal. Dari hal di atas dapat diketahui makna hati lebih umum daripada akal, karena akal adalah sebuah cahaya yang berada dalam hati dan ia mengerjakan sesuatu sesuai dengan pekerjaan-pekerjaan yang dilakukan oleh hati. ${ }^{13}$

Sedangkan tubuh, jasad atau raga adalah bangunan berupa struktur benda yang dapat dirasakan dan dipegang. Oleh karena itu jasad akan punah setelah meninggal. Beda halnya dengan nafs yang kekal sampai hari perhitungan atau hari Kiamat. Oleh karena itu terdapat perbedaan antara nafs dengan jasad sebagaimana firman Allah dalam surat Ali 'Imran (3) ayat 185 berikut ini:

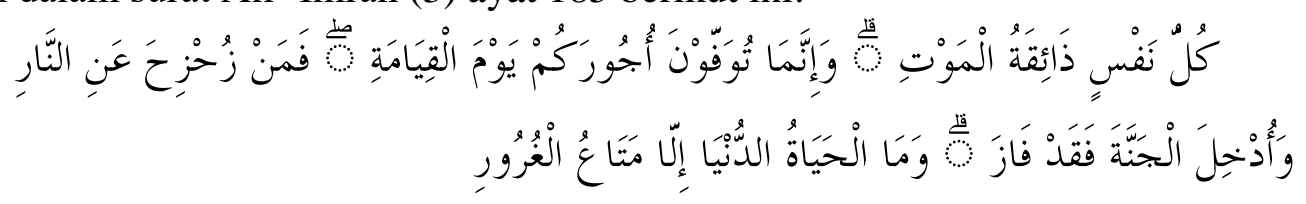

Tiap-tiap yang berjiwa akan merasakan mati. Dan sesungguhnya pada hari kiamat sajalah disempurnakan pahalamu. Barangsiapa dijauhkan dari neraka dan dimasukkan ke dalam syurga, maka sungguh ia telah beruntung. Kehidupan dunia itu tidak lain hanyalah kesenangan yang memperdayakan.

Ayat tersebut membuktikan bahwasanya jiwa tidak mati bersamaan dengan matinya raga karena Allah menjadikan nafs dapat merasakan kematian (dzaiqah almawt) dan untuk merasakannya maka seyogyanya ia masih ada ketika merasakan. Jadi, dapat disimpulkan bahwa jasad adalah tempat bersandarnya jiwa, jasad

\footnotetext{
12 al-Barash, Afat al-Nafs., 30.

${ }^{13}$ Ibid., 31 .
} 
merupakan panggung untuk menyelesaikan tugas-tugas yang dihasilkan dari hubungan antara raga dan nafs atau jiwa. ${ }^{14}$

Sementara itu Ruh adalah bagian gaib atau yang tidak terlihat dari manusia. Ia termasuk salah satu rahasia di antara banyaknya rahasia Allah. Ruh dalam alQur'an mempunyai beberapa makna, di antaranya adalah: Jibril As, wahyu alQur'an, penguat dan kemenangan, Rasulullah Saw. Di samping itu, ruh juga mempunyai beberapa sifat, di antaranya adalah bersemayam dalam jasad, bisa keluar dari jasad, bisa memegang dan mengirim sesuatu. Maka ruh bisa naik, kemudian kembali dan memegang kendali, akan tetapi ia bagian terpisah dari jasad atau badan. ${ }^{15}$

Dari penjelasan di atas dapat diketahui bahwa pengertian yang paling umum dari kata nafs menunjukkan arti menyeluruh yang terdapat dalam manusia sebagai makhluk hidup (jiwa dan diri). Sedangkan lafal qalb (hati) menunjukkan arti unsur penyadar dan emosional yang ada dalam diri manusia. Sementara itu ruh hanya sebatas pada dzat yang berasal dari Allah yang berhubungan dengan kehidupan manusia yang bertujuan untuk membedakan antar mahluk. Sedangkan aqlu (akal) adalah gambaran petunjuk, pemahaman dan pemikiran. ${ }^{16}$

\section{Macam-Macam Nafs}

Terdapat beberapa macam nafs sebagaimana disebut dalam al-Quran yaitu:

a. al-Nafs al-Amarah bi al-Su' (jiwa yang memerintahkan kepada kejelekan). Nafs jenis ini menggambarkan sisi jelek dari manusia. Hal ini sebagaimana firman Allah dalam surat Yusuf (12) ayat 53 berikut ini;

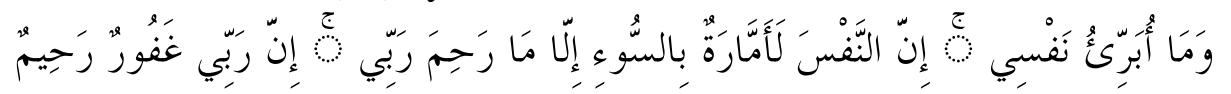

Dan aku tidak membebaskan diriku (dari kesalahan), karena sesungguhnya nafsu itu selalu menyuruh kepada kejahatan, kecuali nafsu yang diberi rahmat oleh Tuhanku. Sesungguhnya Tuhanku Maha Pengampun lagi Maha Penyanyang.

b. al-Nafs al-Lawwamah (jiwa yang mencela)

Maksud dari nafs ini adalah nafs yang menyesali kejadian-kejadian yang sudah lewat dan mencelanya. Nafs ini berjalan sesuai dengan aturan yang telah ditetapkan oleh Allah sebagaimana firman Allah dalam surat al-Qiyamah (75) ayat 1-2 berikut ini:

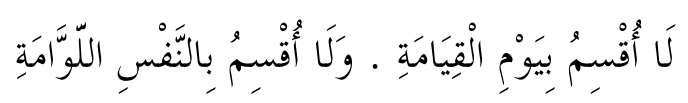

Aku bersumpah demi hari kiamat. Dan aku bersumpah dengan jiwa yang amat menyesali (dirinya sendiri).

Maksud menyesali diri sendiri di sini adalah menyesali kenapa ia tidak berbuat kebaikan semasa hidupnya di dunia.

${ }^{14}$ Ibid, 32.

${ }^{15}$ Ibid, 33-34.

16 Zayn Husayn Yasin, Alfaz Ahwal al-Nafs wa Sifatuha fi al-Qur'an al-Karim (Palestina: Maktabah Jami'ah al-Najah al-Wataniyyah, 2009), 40. 
c. al-Nafs al-Mutmainnah (jiwa yang tenang). ${ }^{17}$

Nafs Mutmainnah adalah jiwa yang tenang yang selalu menyandarkan dirinya kepada Allah Swt dengan berdzikir. Inti dalam jiwanya adalah keimanan dan rindu berjumpa dengan-Nya, sebagaimana firman Allah dalam surat al-Fajr (89) ayat 2730 berikut ini:

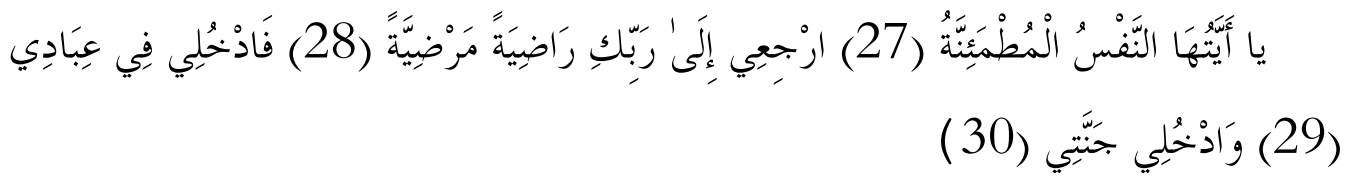

27. Hai jiwa yang tenang; 28. Kembalilah kepada Tuhanmu dengan hati yang puas lagi diridhai-Nya; 29. Maka masuklah ke dalam jama'ah hamba-hamba-Ku; 30. Masuklah ke dalam syurga-Ku.

Allah telah menciptakan manusia disertai akal dan syahwat, menciptakan malaikat disertai akal tanpa syahwat, menciptakan hewan disertai syahwat tanpa akal, maka al-nafs pada manusia mempunyai beberapa sifat, di antaranya adalah sebagai berikut:

a. Sifat ketuhanan, seperti sombong, cinta pujian, sifat ini seharusnya berlaku hanya untuk Allah.

b. Sifat kehambaan, seperti tunduk kepada Allah, tawadu', kasih sayang, saling cinta dan lain sebagainya.

c. Sifat kehewanan, seperti makan, tidur, minum, nikah, berhubungan badan dan lain sebagainya.

d. Sifat kesetanan, seperti berbohong, sombong, menipu, suka berselisih dan lain sebagainya. ${ }^{18}$

Walid Rashid al-'Iyasarah mengatakan bahwa Nafs pada manusia mempunyai beberapa ciri, di antaranya adalah: mempunyai syahawat (keinginan), lemah, tergesa-gesa, mempunyai kemampuan untuk membedakan dan memilih, jelas atau terang, dan mempunyai kemampuan menyiapkan diri untuk belajar. ${ }^{19}$

\section{Karakteristik Jiwa Manusia}

Ketika ayat-ayat al-Qur'an dikaji, terutama yang berkaitan dengan jiwa manusia, maka didapati bahwa jiwa manusia mempunya karakteristik, di antaranya adalah sebagai berikut;

a. Jiwa manusia mempunyai insting alami untuk mengetahui Allah sang pencipta. Insting ini biasanya disebut perasaan keagamaan. Allah berfirman dalam surat al-A'raf (7) ayat 172-173:

\footnotetext{
${ }^{17}$ al-'Iyasarah, Mafhum al Nafs., 31-32.

${ }^{18}$ Muhammad al-Amin Sulaykh, Alfaz al-Nafs fi al-Qur'an al-Karim Qira'ah fi al-Dalalah (t.t: Maktabah Jami'ah Ziyan 'Ashur, 2016), 39

19 al-'Iyasarah, Mafhum al Nafs., 35.
} 


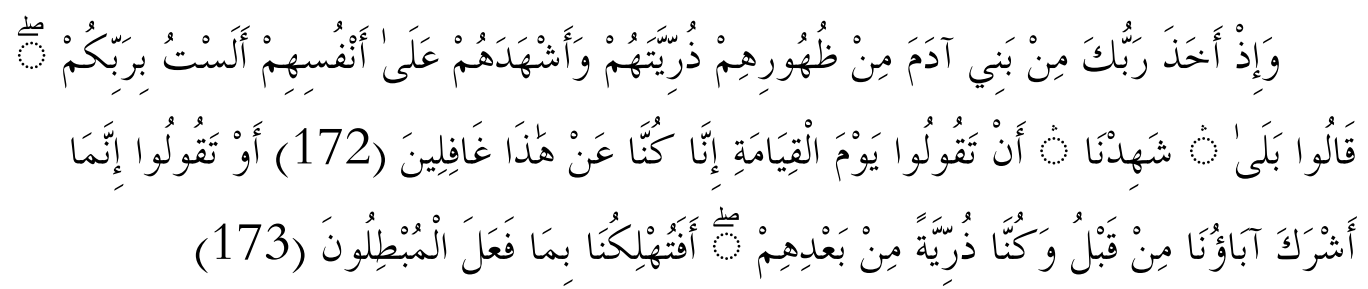

172. Dan (ingatlah), ketika Tuhanmu mengeluarkan keturunan anak-anak Adam dari sulbi mereka dan Allah mengambil kesaksian terhadap jiwa mereka (seraya berfirman): "Bukankah aku ini Tuhanmu?" Mereka menjawab: "Betul (Engkau Tuban kami), kami menjadi saksi". (Kami lakukan yang demikian itu) agar di hari kiamat kamu tidak mengatakan: "Sesungguhnya Kami (Bani Adam) adalah orang-orang yang lengah terhadap ini (keesaan Tuhan)".

173. Atau agar kamu tidak mengatakan: "Sesungguhnya orang-orang tua kami telah mempersekutukan Tuhan sejak dahulu, sedang kami ini adalah anak-anak keturunan yang (datang) sesudah mereka. Maka, apakah Engkau akan membinasakan kami karena perbuatan orang-orang yang sesat dahulu?"

Ayat di atas menunjukkan bahwa insting keagamaan itu telah diciptakan oleh Allah pada manusia sejak manusia itu masih berada di tulang sulbi orang tuanya. Sehingga, tidak ada alasan bagi orang-orang yang musyrik untuk mengatakan bahwa mereka menjadi musyrik karena bapak-bapak mereka dahulu telah mempersekutukan Tuhan.

b. Terombang-ambing, berlebihan dan keluar dari batasan yang telah ditentukan. Allah berfirman dalam surat al-Nisa' (4) ayat 129:

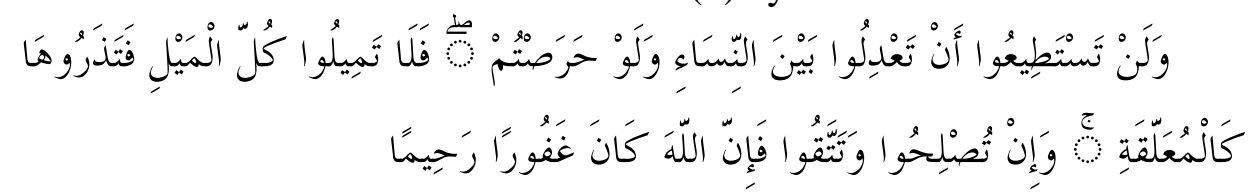

Dan kamu sekali-kali tidak akan dapat berlaku adil di antara isteri-isteri(mu), walaupun kamu sangat ingin berbuat demikian. Karena itu janganlah kamu terlalu cenderung (kepada yang kamu cintai), sehingga kamu biarkan yang lain terkatungkatung. Dan jika kamu mengadakan perbaikan dan memelihara diri (dari kecurangan), maka sesungguhnya Allah Maha Pengampun lagi Maha Penyayang.

c. Mampu mengetahui kebaikan dan keburukan. Allah berfirman dalam surat al-Shams (91) ayat 7-10:

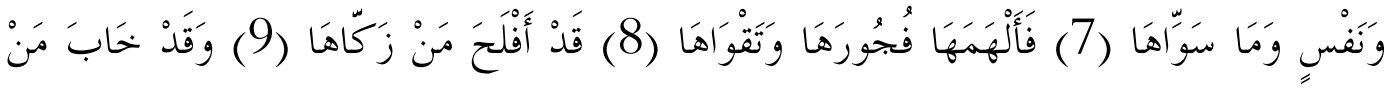

$$
\begin{aligned}
& \text { دَسَّاهَا (10) }
\end{aligned}
$$

7. Dan jiwa serta penyempurnaannya (ciptaannya). 8. Maka Allah mengilhamkan kepada jiwa itu (jalan) kefasikan dan ketakwaannya. 9. Sesungguhnya beruntunglah orang yang mensucikan jiwa itu. 10. Dan sungguh merugilah orang yang mengotorinya.

d. Sangat hati-hati dalam menjaga kebaikan dan berkeluh kesah terhadap kejelekan. Allah berfiman dalam surat Fussilat (41) ayat 49: 


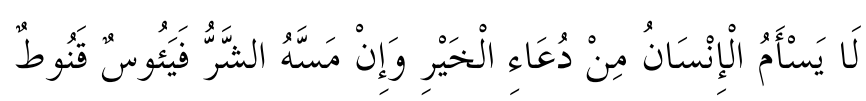

Manusia tidak jemu memohon kebaikan, dan jika mereka ditimpa malapetaka dia menjadi putus asa lagi putus harapan.

e. Tergesa-gesa. Allah berfirman dalam surat al-Anbiya' (21) ayat 37:

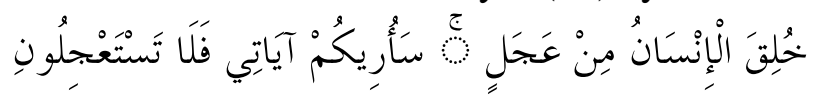

Manusia telah dijadikan (bertabiat) tergesa-gesa. Kelak akan Aku perIihatkan kepadamu tanda-tanda azab-Ku. Maka janganlah kamu minta kepada-Ku mendatangkannya dengan segera.

f. Ragu-ragu dan lemah. Allah berfirman dalam surat al-Nisa' (4) ayat 28:

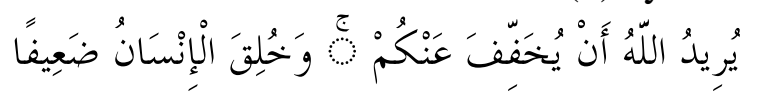

Allah hendak memberikan keringanan kepadamu, dan manusia dijadikan bersifat lemah.

g. Memberontak dan sombong. Allah berfirman dalam surat Saba' (32) ayat 34-35:

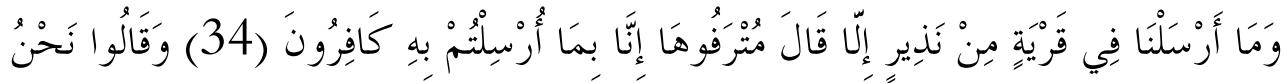

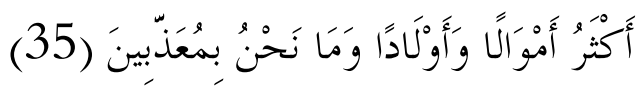

Dan Kami tidak mengutus kepada suatu negeri seorang pemberi peringatan pun, melainkan orang-orang yang hidup mewah di negeri itu berkata: "Sesungguhnya kami mengingkari apa yang kamu diutus untuk menyampaikannya". Dan mereka berkata: "Kami lebih banyak mempunyai harta dan anak- anak (daripada kamu) dan kami sekali-kali tidak akan diazab.

h. Ingkar. Allah berfirman dalam surat al-Sajadah (32) ayat 9:

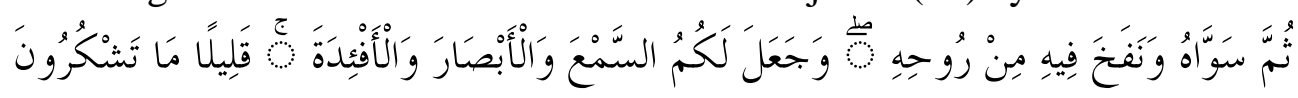

Kemudian Dia menyempurnakan dan meniupkan ke dalamnya roh (ciptaan)Nya dan Dia menjadikan bagi kamu pendengaran, penglihatan dan hati; (tetapi) kamu sedikit sekali bersyukur.

i. Suka mengumpulkan harta. Allah berfirman dalam surat al-Fajr (89) ayat 19-20:

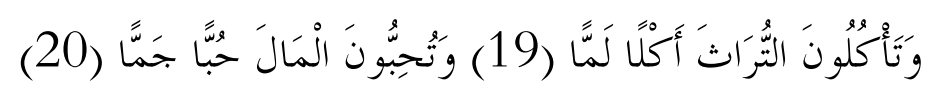

Dan kamu memakan harta pusaka dengan cara mencampur baurkan (yang halal dan yang bathil). Dan kamu mencintai harta benda dengan kecintaan yang berlebihan.

j. Perasaan-perasaan yang ada pada jiwa manusia mengikuti emosinya. Allah berfirman dalam surat al-Kahfi (18) ayat 6 :

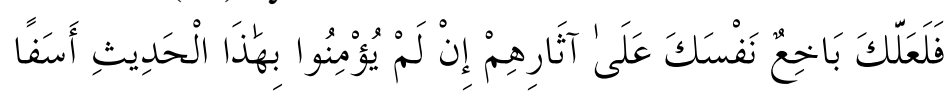


Maka (apakah) barangkali kamu akan membunuh dirimu karena bersedih hati setelah mereka berpaling, sekiranya mereka tidak beriman kepada keterangan ini (Al-Quran).

k. Mempunyai syahwat (kesenangan) dan kemampuan untuk berhubungan badan. Allah berfirman dalam surat Fussilat (41) ayat 31:

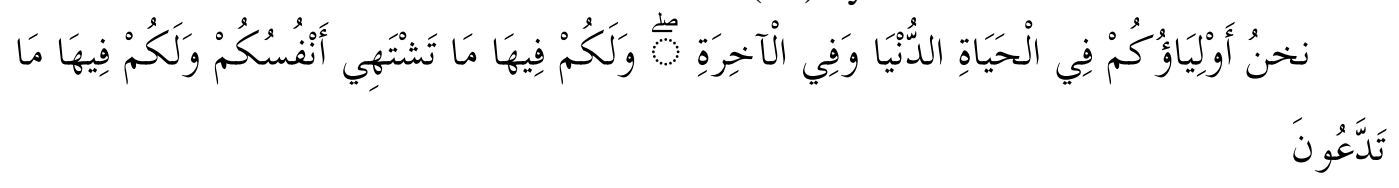

Kamilah pelindung-pelindungmu dalam kehidupan dunia dan akhirat; di dalamnya kamu memperoleh apa yang kamu inginkan dan memperoleh (pula) di dalamnya apa yang kamu minta.

1. Mempunyai rasa takut dan harapan. Allah berfirman dalam surat al-Nisa' (4) ayat 100 :

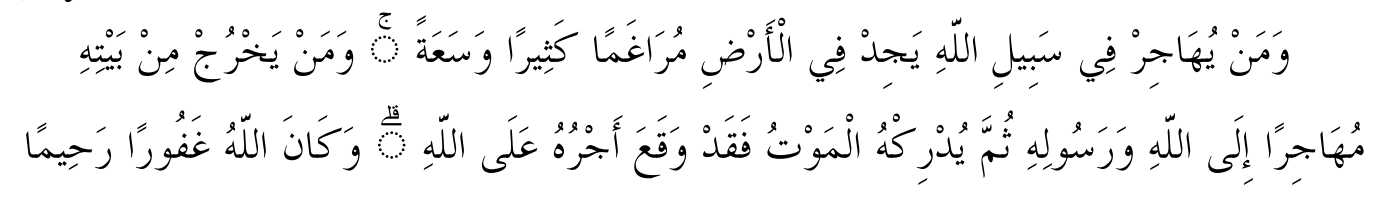

Barangsiapa berhijrah di jalan Allah, niscaya mereka mendapati di muka bumi ini tempat hijrah yang luas dan rezki yang banyak. Barangsiapa keluar dari rumahnya dengan maksud berhijrah kepada Allah dan Rasul-Nya, kemudian kematian menimpanya (sebelum sampai ke tempat yang dituju), maka sungguh telah tetap pahalanya di sisi Allah. Dan adalah Allah Maha Pengampun lagi Maha Penyayang.

m. Dermawan dan pelit. Allah berfirman dalam surat al-Hashr (59) ayat 9 dan surat al-Isra' (41) ayat 31 sebagai berikut:

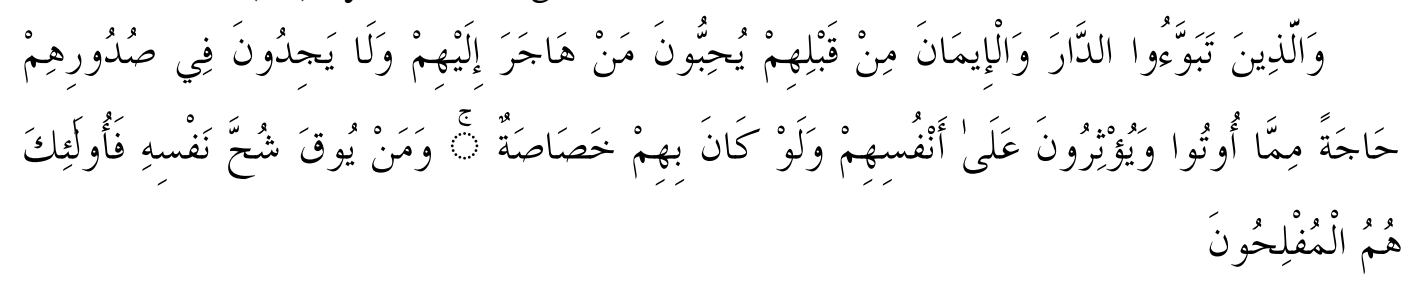

Dan orang-orang yang telah menempati kota Madinah dan telah beriman (Anshor) sebelum (kedatangan) mereka (Muhajirin), mereka (Anshor) 'mencintai' orang yang berhijrah kepada mereka (Muhajirin). dan mereka (Anshor) tiada menaruh keinginan dalam hati mereka terhadap apa-apa yang diberikan kepada mereka (Muhajirin); dan mereka mengutamakan (orang-orang muhajirin), atas diri mereka sendiri, sekalipun mereka dalam kesusahan. dan siapa yang dipelihara dari kekikiran dirinya, mereka itulah orang orang yang beruntung. (al-Hasyr: 9)

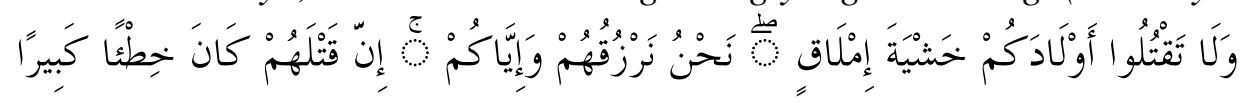

Dan janganlah kamu membunuh anak-anakmu karena takut kemiskinan. Kamilah yang akan memberi rezki kepada mereka dan juga kepadamu. Sesungguhnya membunuh mereka adalah suatu dosa yang besar. (al-Isra: 31) 
n. Dan lain sebagainya. ${ }^{20}$

\section{Penutup}

Kata al-nafs yang terdapat dalam al-Qur'an menunjukkan arti manusia (kecuali kata tersebut terdapat qarinah yang menunjukkan kepada dzat ilahi) dengan susunan ruh dan jasad sebagai sesuatu yang hidup dan sempurna pada semua strukturnya, baik itu raga, akal pikir, dan akhlaq.

al-Nafs mempunyai ciri, macam, dan karakter yang berbeda-beda walaupun pada dasarnya mereka berasal dari jiwa satu yaitu Adam.

\section{Daftar Pustaka}

Al-Qur'an

'Iyasarah (al), Walid Rashid. Mafhum al Nafs fi al-Qur'an al-Karim wa In 'ikasatuh 'Ala al-Minhaj al-Tarbawy fi al-Mujtama' al-Muslim. Saudi: Maktabah Jami'ah al-Mulk, 2017.

Abu Shanab, Ahmad Jum'ah Muhammad. al-Nafs al-Insaniyyah fi Suwaytiha wa Inhirafiha Bayna al-Qur'an al-Karim wa 'Ilm al-Nafs al-Hadis. Saudi: Maktabah Jami'ah Um al-Qura, t.th.

Barash (al), Nu'aymah 'Abd Allah. Afat al-Nafs Kama Yusawwiruha al-Qur'an alKarim. Gaza: Maktabah al-Jami’ah al-Islamiyyah, 2008.

Bayhaqi (al), Abu Bakr Ahmad ibn al-Husayn ibn 'Ali. al-Sunan al-Kubra. Beirut: Dar al-Kutub al-'Ilmiyyah 2002.

Bukhari (al), Abi Abdillah Muhammad ibn Ismail. Sahih al-Bukhari. Beirut: Dar Ibn Kathir, 2002.

Nizami, Raniya Muhammad 'Aziz. al-Nafs wa Haqiqatuha fi al-Qur'an al-Karim. Aleksandria: Maktabah Jami’ah al-Iskandariyah, 2006.

Sulaykh, Muhammad al-Amin. Alfaz al-Nafs fi al-Qur'an al-Karim Qira'ah fi alDalalah. t.t: Maktabah Jami’ah Ziyan 'Ashur, 2016.

Yasin, Zayn Husayn. Alfaz Ahwal al-Nafs wa Sifatuha fi al-Qur'an al-Karim. Palestina: Maktabah Jami'ah al-Najah al-Wataniyyah, 2009.

Shawashrih, 'Atif "Tabiah al-Nafs al-Bashariyah fi Marhalah al-Taklif fi Daw'i alQur'an al-Karim”, Majallah Jami'ah al-Najah li al-Abhas, Vol. 24, No. 1

20 'Atif Shawashrih, "Tabiah al-Nafs al-Bashariyah fi Marhalah al-Taklif fi Daw’I al-Qur'an al-Karim”, Majallah Jami'ah al-Najah li al-Abhas, Vol. 24, No. 1 (2010), 7-13. - 'Ilyan 'Abd Allah al-Hawli, Khasais al-Nafs al-Bashariyah fi al-Qur'an al-Karim wa In'ikasatuha al-Tarbawiyyah (t.t:t.p,t.th), 26. 


\section{Muhammad Arwani Rofi'i}

(2010), 7-13. - 'Ilyan 'Abd Allah al-Hawli, Khasais al-Nafs al-Bashariyah fi al-Qur'an al-Karim wa In'ikasatuha al-Tarbawiyyah. t.t:t.p,t. 